\title{
IDENTIFIKASI NOMINAL UANG KERTAS UNTUK TUNA NETRA BERBASIS MIKROKONTROLLER DENGAN SISTEM SUARA
}

\author{
Agus Pujianto $^{1}$,H. Zainal Abidin ${ }^{2}$,Arief Budi Laksono ${ }^{3}$, \\ Program Studi Teknik Elektro, Fakultas Teknik, Universitas Islam Lamongan ${ }^{1,2,3}$ \\ E-mail:Pujiantogus91@gmail.com ${ }^{1}$,zainalabidin@unisla.ac.id², ariefbudila@gmail.com³
}

\begin{abstract}
Abstrak
Uang merupakan alat yang dipakai untuk transaksi jual dan beli yang sudah digunakan seluruh manusia di penjuru dunia. Sehingga menjadikan uang sebagai barang pokok untuk setiap orang, tidak terkecuali para penyandang disabilitas seperti halnya tunanetra, kelemahan tunanetra dalam melihat dan mengidentifikasi uang dapat menyebabkan tertukar, salah ambil, bahkan bisa tertipu saat melakukan transaksi jual beli. Tujuan dari penelitian ini adalah untuk membantu para penyandang tunanetra dalam mengetahui nominal uang kertas dengan menggunakan sistem suara yang di identifikasi oleh sensor warna TCS230.

Dalam penelitian ini menggunakan metode kualitatif dengan melakukan studi pustaka, pembuatan perangkat, integrasi sistem,pengujian, dan analisa sistem, serta beberapa percobaan dengan sensor warna TCS230 . Hasil Identifikasi nominal uang kertas tersebut kemudian dibaca dengan menggunakan sensor warna TCS230 yang terhubung dengan mikrokontroler atmega 328 dan loudspeaker. Dengan alat identifikasi ini akan dapat diketahui nilai uang kertas rupiah dengan cara meletakan uang kertas rupiah diatas sensor TCS230 maka otomatis sensor membaca nilai RGB , apabila sesuai dengan range yang telah di tentukan olehATMega328 maka nominal uang kertas rupiah akan ditampilkan di layar LCD dan loudspeaker akan mengeluarkan suara yang sama berupa nilai mata uang kertas rupiah tersebut .Sehingga diharapkan alat ini dapat mempermudah tunanetra dalam mengetahui nominal uang kertas sehingga menguranggi terjadinya penipuan nominal uang terhadap tunanetra.
\end{abstract}

Kata kunci :, Sensor warna TCS230,atmega328, loudspeaker.

\begin{abstract}
Money is a tool used for buying and selling transactions that have been used by all people throughout the world. So, money is a staple item for everyone, including persons with disabilities as well as blind people. The weakness of a blind person is seeing and identifying money can cause exchange, wrong take, even they can be fooled when buying or selling. The purpose of this study is to help blind people find out the nominal banknotes by using a sound system that is identified by the TCS230 color sensor.

This study uses a qualitative method by conducting library studies, making devices, system integration, testing, and analyzing systems, as well as several experiments with the TCS230 color sensor. Theresult of identifying o paper money nominal then read it by using TCS230 color sensor which is connected to the atmega 328 microcontroller and the loudspeaker. By using identification device, it will be able to know the value of rupiah banknotes by placing rupiah banknotes over the TCS230 sensor then the sensor automatically reads the RGB value, if it matches the range specified by ATMega328 then the nominal rupiah banknotes will be displayed on the LCD screen and the loudspeaker will issue the same vote in the form of the value of the rupiah paper currency. So that it is hoped that this tool can make it easier for the blind in knowing the nominal paper money so as to reduce the occurrence of nominal money fraud against the visually impaired.
\end{abstract}

Keyword :, TCS230 color sensor,atmega328, loudspeaker.

\section{PENDAHULUAN}

Uang merupakan alat yang dipakai untuk transaksi jual dan beli yang sudah digunakan seluruh manusia di penjuru dunia. Sehingga menjadikan uang sebagai barang pokok untuk setiap orang, tidak terkecuali para penyandang disabilitas seperti halnya tunanetra, kelemahan tunanetra dalam melihat dan mengidentifikasi uang dapat menyebabkan tertukar, salah ambil, bahkan bisa tertipu saat melakukan transaksi jual beli. Di era moderen seperti ini, transaksi jual beli merupakan suatu hal yang tidak dapat lepas dari kehidupan orang sehari-hari guna memenuhi segala kebutuhan hidup. Dunia masa kini telah mengenal beberapa alat tukar barang antara lain emas dan kartu kredit, yang menggantikan sistem barter dizaman dahulu beberapa ratus tahun lalu.Tapi diantara semua media tersebut, yang populer ialah penggunaan mata uang sebagai alat untuk transaksi jual beli. pada saat ini masih ada 
orang yang kesulitan untuk mengenali nominal uang, diantaranya penyandang tunanetra dan katarak. serta kurangnya kejujuran antara penjual dan pembeli terhadap penyandang katarak maupun tunanetra. Hal ini Menjadikan para penyandang dan penderita tunanetra sering tertipu disebabkan kurang mengetahui nominal uang yang dipegang.Para penyandang tunanetra menggunakan dua cara konvensional seperti menyusun dan mengurutkan nilai uang kertas, tunanetra juga dapat mengenali ada berapa saja nominal uang yang masih dimilikinya dengan membuat lipatan pada uang tersebut. Cara ini lebih mudah tapi tunanetra harus menggunakan ingatanya untuk membedakan nilai nominal uang.

Pentingnya dalam hal mengetahui dan mengenali nominal uang kertas agar tidak tertipu oleh oknum yang tidak bertanggung jawab saat melakukan transaksi jual beli, penulis ingin membantu para penyandang tunanetra dengan membuat suatu alat pendeteksi nominal uang yang menggunakan sensor warna sebagai input nilai nominal uang kertas, dengan cara mendeteksi setiap warna uang kertas pada bagian tertentu, yang diproses oleh mikrokontroller atmega 328 dan outputnya suara.

1. Berdasarkan latar belakang diatas berkaitan dengan proses pembuatan dan perancangan alat identifikasi nominal uang kertas bagi tunanetra berbasis ATMega 328P yang dapat dirumuskan sebagai berikut : Berapa besar akurasi nilai sensor warna TCS230 terhadap deteksi warna mata uang menggunakan mikrikontroller ATMega328 ?

2. Bagaimana respon modul suara DF miniplayer, LCD dan loudspeaker ketika mendeteksi mata uang ?

\section{METODE PENELITIAN}

\subsection{Tahap Penelitian}

Pada tahap ini akan membahas mengenai metode penelitian dengan melakukan studi literatur, pembuatan perangkat, integrasi sistem, pengujian, dan analisa sistem, serta beberapa percobaan dengan sensor warna TCS230 . Hasil Identifikasi nominal uang kertas tersebut kemudian dibaca dengan menggunakan sensor warna TCS230 yang terhubung dengan mikrokontroler atmega 328 dan loudspeaker.

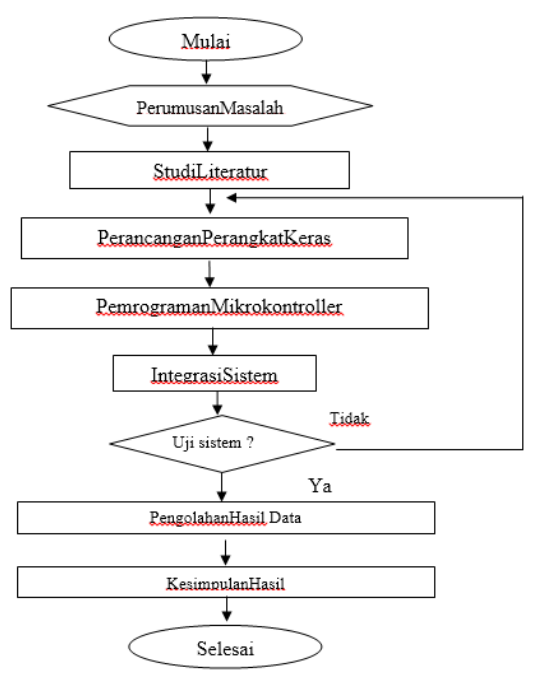

Gambar 1. diagram proses penelitian

\subsection{Blok Diagram}

Adapun diagram sistemnya sebagai berikut

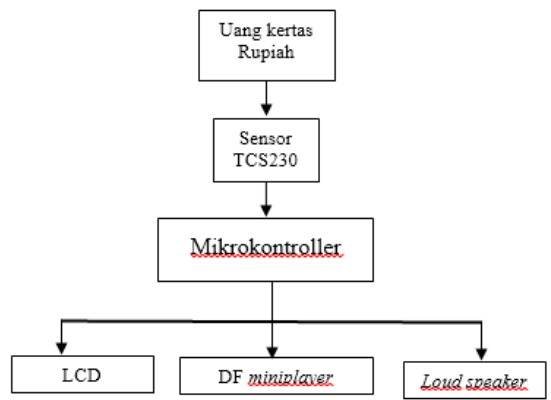

Gambar 2 Blok Diagram Rangkaian

Dari blok diagram diatas menunjukkan cara kerja sistem secara keseluruhan. Sensor Chip TCS230 memiliki beberapa photodetector, dengan masing-masing filter warna yaitu, merah, hijau, biru, dan clear. Filter-filter tersebut didistribusikan pada masing-masing array. Module ini memiliki oscilator yang menghasilkan pulsa square yang frekuensinya sama dengan warna yang dideteksi. Warna dari uang kertas Rupiah berfungsi sebagai masukan, yang akan terdeteksi oleh sensor TCS230 yang telah di program melalui mikrokontrollerATMega328 sebagai processing. Output sensor TCS230 berupa data analog yang dihubungkan ke pin analog input pada arduino. Data analog ini dikonversikan menjadi data ADC untuk mengubah tampilan menjadi nilai RGB yang akan terlihat pada LCD. Ketika nilai RGB yang terlihat pada LCD sesuai dengan data pada mikrokontroller maka arduino akan memerintah DF miniplayeruntuk memutar suara pada loudspeaker.

\subsection{Metode Pengujian Rangkaian}

A. Pengujian Sensor TCS230

Pengujian sensor TCS230 dapat dilakukandengan memberi tegangan listrik, kemudian dihubungkan dengan pin arduino selanjutnya sensor TCS230 akan mengeluarkan arus yang besarnya sebanding dengan kadar warna dasar cahaya yang diterimanya. 
B. Pengujian Tampilan LCD

Pengujian tampilan LCD dilakukan dengan cara membandingkan tampilan LCD dengan data yang dimasukkan.

C. Pengujian Loudspeaker

Pengujian dapat dilakukan dengan menghubungkan pin arduino. Pengujian Loudspeaker ini dilakukan dengan tujuan sebagai indicator suara. Untuk mendapatkan hasil yang baik dalam pengujian, maka proses pengujian Loudspeaker dihubungkan pada pin-pin mikrokontroller. Apabila Loudspeake rmengeluarkan bunyi, maka Loudspeaker berfungsi dengan baik dan siap untuk digunakan.

D. Pengujian DFMiniplayer

DFMiniplayer adalah modul pemutar file audio dengan support format audio seperti file MP3. Pengujian DFMiniplayer digunakan untuk menyampaikan informasi yaitu nilai mata uang Rupiah kepada pengguna.

\subsection{Rangkaian Alat Keseluruhan}

Pada tahap ini merupakan proses penggabungan alat secara keseluruhan, perangkat tersebut terdiri dari sensor TCS230, LCD, DF miniplayer, mikrokontroller ATMega 328, dan loudspeakrer.Semua rangkaian dicetak pada PCB dan masing-masing komponen dipasang sesuai gambar.Berikut adalah rangkaian perangkat keras yang telah dirancang secara keseluruhan.

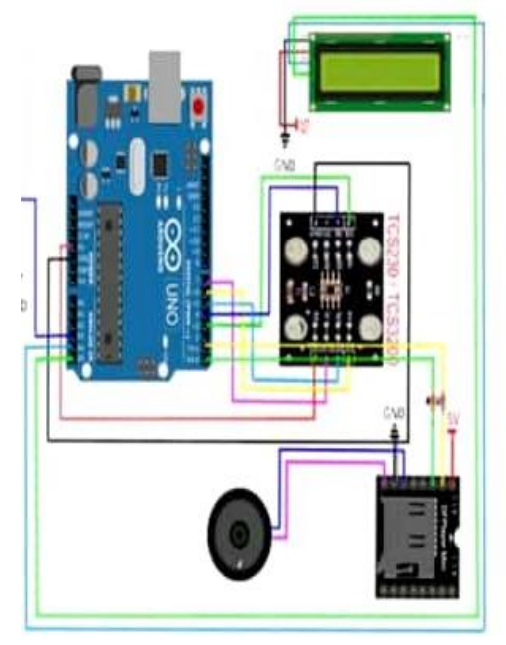

Gambar 3 Rangkaian Alat Keseluruhan

\section{Hasil dan pembahasan}

Dalam tahap ini akan membahas hasil terdapat beberapa hasil pendataan ,perakitan, percobaan dan pengujian diantaranya hasil data selama observasi di lapangan, perakitan perangkat keras, hasil perangkat keras, hasil pengujian peragkat lunak dan hasil keseluruhan

Di bab ini akan dibahas tentang pengujian sistem yang telah dibuat serta pembahasan dari pengujian. Pengujian disimulasikan pada system dengan tujuan untuk mengetahui kendala dari system dan sudah sesuai dengan perencanaan yang telah dibuat. Pengujian ini dimulai secara terpisah tiap alat dan kemudian dilakukan kedalam system secara keseluruhan.

Pada bab ini, pengujian yang dilakukan diantaranya

1. Pengujian Sensor TCS230

2. Pengujian Mikrokontroller

3. Pengujian LCD

4. Pengujian Df Miniplayer

5. Pengujian loudspeaker

6. Pengujian Powersupplay

7. Pengujian Alat Secara Keseluruhan

\subsection{Hasil Pengujian \\ Pengujian Sensor TCS230}

Pengujian sensor TCS230 dilakukan untuk mendeteksi warnah setiap uang yang berbeda, terutama uang rupiah yang tahun emisinya 2016 dalam kondisi yang baik. Pengujian sensor ini menggunakan 7 Mata uang rupiah kertas yang bernominal mulai $\mathrm{Rp}, 100.000$, Rp. 50.000. Rp. 20.000. Rp. 10.000. Rp. 5000. Rp. 2000. Rp. 1000, yang sebelumnya sensor TCS230 telah dimasukkan program melalui board arduino dan programnya telah disimpan kedalam IC mikrokontroller ATMega 328p. Untuk mendapatkan hasil yang baik dan maksimal, adapun pengujian sensor TCS230 tampak pada gambar 3.1 di bawah.

Untuk mendapatkan hasil yang baik, maka proses pengujian sensor dilakukan dengan menghubungkan kaki sensor TCS230 pada pin pin arduino dengan memastikan indikator lampu sensor TCS230 tersebut menyala. Kemudian sensor TCS230 dimasukkan program melalui software arduino kedalam mikrokontroller ATMega328. Besar nilai mata uang Rupiah dapat dilihat melalui tampilan LCD.

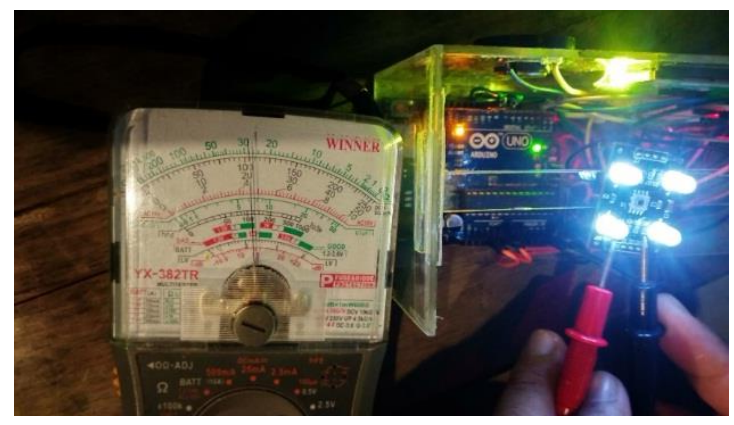

Gambar4. Pengujian Sensor TCS230

Dari gambar diatas merupakan proses pengujian sensor TCS230 yang telah dimasukkan program. Hasil dari pengujian sensor TCS230 disajikan dalam table sebagai berikut : 
JEECOM, Vol. 2, No. 2, Oktober 2020

Tabel 1 Pengujian Sensor TCS230

\begin{tabular}{|c|c|c|c|c|}
\hline \multirow{2}{*}{ Uangkertas } & \multirow{2}{*}{ Ujicoba } & \multicolumn{2}{|c|}{ Terdeteksi } & \multirow{2}{*}{ Presentase } \\
\cline { 3 - 5 } & & Ya & Tidak & \\
\hline Rp. $100.000,-$ & $10 \mathrm{x}$ & 9 & 1 & $90 \%$ \\
\hline Rp. $50.000,-$ & $10 \mathrm{x}$ & 10 & - & $100 \%$ \\
\hline Rp. $20.000,-$ & $10 \mathrm{x}$ & 10 & - & $100 \%$ \\
\hline Rp. $10.000,-$ & $10 \mathrm{x}$ & 10 & - & $100 \%$ \\
\hline Rp. $5.000,-$ & $10 \mathrm{x}$ & 8 & 2 & $80 \%$ \\
\hline Rp. $2.000,-$ & $10 \mathrm{x}$ & 10 & - & $100 \%$ \\
\hline Rp. $1000,-$ & $10 \mathrm{x}$ & 10 & - & $100 \%$ \\
\hline
\end{tabular}

Dari hasil tabel pengujian di atas, di lakukan pengujian terhadap tujuh mata uang rupiah yang berbeda, melihat hasil yg di dapat deteksi sensor TCS230 menghasilkan nilai presentase yang berbeda-beda. Untuk mengetahui berapa besar nilai akurasi dari sensor dapat di lakukan dengan mengambil nilai rata-rata dari keberhasilan uji coba dengan rumus; prosentase

$$
\begin{aligned}
& =\frac{\text { totalkeberhasilanujicoba }}{\text { totalujicoba }} \times 100 \% \\
& =\frac{\mathbf{6 7}}{\mathbf{7 0}} \times 100 \%=95,7 \%
\end{aligned}
$$

Adapun nilai RGB yang di jadikan sebagai batasan-batasan untuk membedakan setiap nominal uang kertas rupiah dapat dijelaskan pada tabel di bawah ini ;

\begin{tabular}{|c|c|c|c|c|c|}
\hline no & Nominal & nilai & $\mathbf{R}$ & G & B \\
\hline \multirow[t]{2}{*}{1} & \multirow[t]{2}{*}{ Rp100.000,- } & Atas & 71 & 75 & 58 \\
\hline & & bawah & 66 & 63 & 50 \\
\hline \multirow[t]{2}{*}{2} & \multirow[t]{2}{*}{ Rp50.000,- } & Atas & 123 & 89 & 61 \\
\hline & & Bawah & 105 & 76 & 54 \\
\hline \multirow[t]{2}{*}{3} & \multirow[t]{2}{*}{ Rp20.000,- } & Atas & 83 & 67 & 56 \\
\hline & & Bawah & 74 & 61 & 48 \\
\hline \multirow[t]{2}{*}{4} & \multirow[t]{2}{*}{ Rp10.000,- } & Atas & 87 & 82 & 54 \\
\hline & & bawah & 76 & 69 & 46 \\
\hline \multirow[t]{2}{*}{5} & \multirow[t]{2}{*}{ Rp5000,- } & Atas & 66 & 77 & 71 \\
\hline & & Bawah & 60 & 70 & 64 \\
\hline \multirow[t]{2}{*}{6} & \multirow[t]{2}{*}{ Rp2000,- } & Atas & 81 & 82 & 70 \\
\hline & & Bawah & 72 & 69 & 62 \\
\hline \multirow[t]{2}{*}{7} & \multirow[t]{2}{*}{ Rp1000,- } & Atas & 86 & 90 & 87 \\
\hline & & Bawah & 75 & 77 & 79 \\
\hline
\end{tabular}

Tabel 2 nilai RGB

\subsection{Pengujian Mikrokontroller}

Mikrokontroller berfungsi sebagai input program sehingga alat dapat bekerja sesuai dengan system. Pengujian mikrokontroller dilakukan untuk memastikan dapat bekerja dengan baik. Adapun pengujian mikrokontroller tampak pada gambar 5 .

Proses pengujian mikrokontroller dihubungkankan dengan tegangan yang memiliki nilai 5 volt. Apabila lampu indicator mikrokontroller menyala, maka mikrokontroller dalam kondisi baik dan bisa digunakan.

Tabel 3. Hasil Pengujian Mikrokontroller

\begin{tabular}{|c|l|l|l|}
\hline NO & \multicolumn{1}{|c|}{ INPUT } & \multicolumn{1}{|c|}{ OUTPUT } & \multicolumn{1}{|c|}{ STATUS } \\
\hline 1 & 0 Volt & 0 Volt & Mati \\
\hline 2 & 5 Volt & 5 Volt & Nyala \\
\hline
\end{tabular}

Dari table pengujian diatas, menunjukkan bahwa apabila mikrokontroller di beri tengangan sebesar 5 volt ,maka status Mikrokontroller akan menyala. Sedangkan apabila mikrokontroller tidak diberitegangan, maka status mikrokontroller akan mati. Hal itu menandakan bahwa mikrokontroller berfungsi dengan baik.

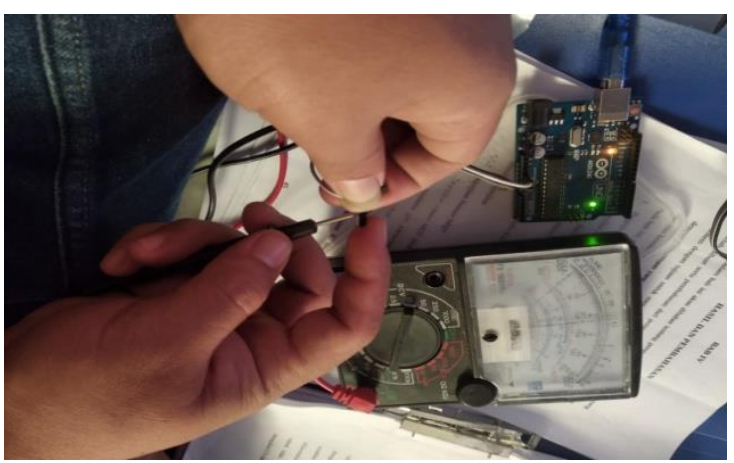

Gambar 5 Pengujian Mikrokontroller

\subsection{Pengujian LCD}

Pengujian LCD dilakukan untuk menampilkan nilai mata uang rupiah yang tertera pada LCD dan juga untuk memastikan LCD dapat bekerja dengan baik, sehingga dalam mendeteksi nilai mata uang rupiah akan mendapatkan data yang baikUntuk mendapatakan hasil yang baik, maka proses pengujian LCD dilakukan dengan menghubungkan kaki - kaki LCD pada pin - pin arduino. Kemudian dimasukkan program kedalam IC mikrokontroller ATMega328 melalui software arduino. Adapun rangkaian pengujian LCD tampak pada gambar 6. 
JEECOM, Vol. 2, No. 2, Oktober 2020

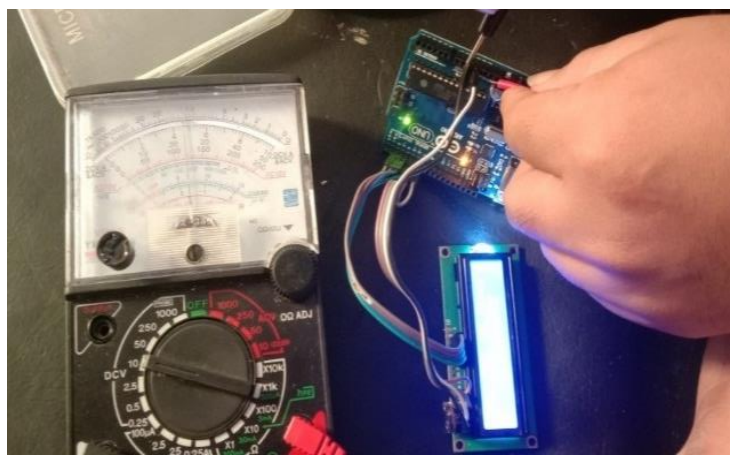

Gambar 6. pengujian LCD

Dari pengujian pada gambar 6 didapatkan hasil pengujian yang dapat dilihat pada table sebagai berikut :

Tabel 4 Hasil Pengujian LCD

\begin{tabular}{|c|c|c|c|}
\hline NO & INPUT & OUTPUT & STATUS \\
\hline 1 & 0 Volt & 0 Volt & off \\
\hline 2 & 5 Volt & 5 Volt & on \\
\hline
\end{tabular}

Dari table pengujian diatas, menunjukkan bahwa apabila LCD diberi tegangan sebesar 5 volt, maka status LCD akanon. Sedangkan apabila LCD tidak diberitegangan, maka status LCD akanoff. Hal itu menandakan bahwa LCD berfungsi dengan baik

\subsection{Pengujian $D F$ playermini}

Pengujian DFplayermini dapat dilakukan dengan memberi tegangan sebesar 5 volt, yang kemudian dihubungkan dengan pin-pin arduino. proses pengujian $D F$ playermini dapat dihubungkankan dengan tegangan yang memiliki nilai 5 volt. Apabila lampu indikator $D F$ playermini menyala, maka $D F$ playermini dalam kondisi baik dan bisa digunakan.

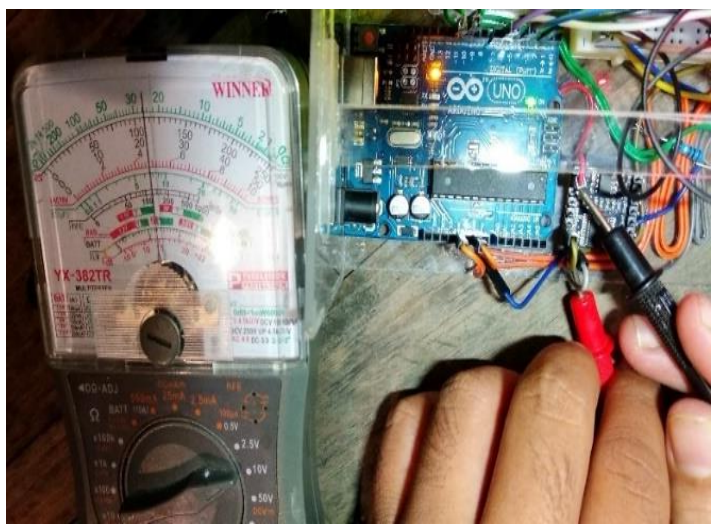

Gambar 7. pengujian DFminiplayer
Tabel 5 Pengujian DF playermini

\begin{tabular}{|c|l|l|l|}
\hline NO & \multicolumn{1}{|c|}{ INPUT } & \multicolumn{1}{|c|}{ OUTPUT } & \multicolumn{1}{|c|}{ STATUS } \\
\hline 1 & 0 Volt & 0 Volt & Off \\
\hline 2 & 5 Volt & 5 Volt & On \\
\hline
\end{tabular}

Dari table pengujian diatas, menunjukkan apabila DF playermini diberitegangan sebesar 5 volt, maka status $D F$ playermini akan menyala. Sedangkan apabila $D F$ playermini tidak diberi tegangan, maka status DFplayermini akan mati. Hal itu menandakan bahwa $D F$ playermini berfungsi dengan baik

\subsection{Pengujian loudspeaker}

Pengujian loudspeaker dapat dilakukan dengan cara menghubungkan pin arduino. Pengujian loudspeaker ini dilakukan dengan tujuan apabila sensor TCS230 mendeteksi nilai mata uang rupiah maka loudspeaker akan berbunyi sesuai dengan nominal uang kertas rupiah tersebut. Adapun rangkaian pengujian loudspeaker tampak pada gambar 8. Untuk mendapatkan hasil yang baik dalam pengujian, maka proses pengujian dilakukan dengan menghubungkan pada pin - pin arduino atau tegangan sebesar 5 volt.

Tabel 6 Pengujian loud speaker

\begin{tabular}{|c|c|c|c|}
\hline NO & INPUT & OUTPUT & STATUS \\
\hline 1 & 0 Volt & 0 Volt & Nyala \\
\hline 2 & 5 Volt & 5 Volt & Mati \\
\hline
\end{tabular}

Dari table pengujian diatas, menunjukkan ketika loudspeaker diberitegangan sebesar 5 volt, maka status loudspeaker akan on/ menyala. Sedangkan apabila loudspeaker tidak diberi tegangan, maka status loudspeaker akan off/mati . Hal itu menandakan bahwa loudspeaker berfungsi dengan baik.

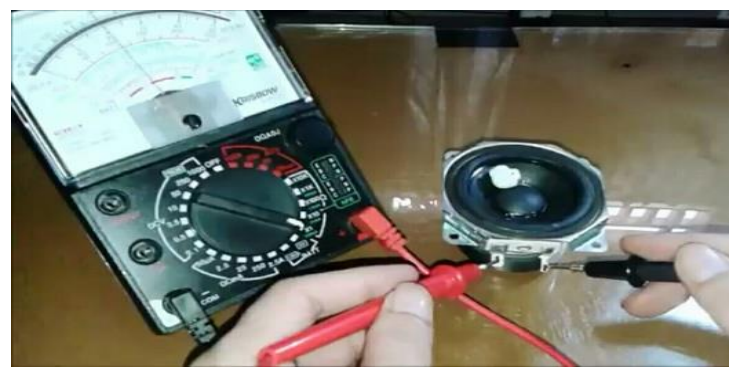

Gambar 8. Pengujian loud speaker 


\subsection{Pengujian Rangkaian Keseluruhan}

Tahap ini bertujuan untuk mengetahui kinerja rangkaian keseluruhan yang meliputi pengujian sensor TCS230, pengujian LCD, pengujian DFminiplayer, dan pengujian loudspeaker. Proses pengujian dilakukan dengan memasukkan mata uang kertas (Rupiah) kedalam alat identifikasi uang kertas berbasis ATMega328 dengan sistem suara. Apabila tertedeksi nilai mata uang rupiah, maka system akan berkerja dengan menampilkan nilai nominal kelayar LCD, dan loud speaker akan mengeluarkan suara sesuai dengan nominal uang kertas rupiah yang telah terdeteksi oleh sensor. Hasil pengujian dapat dilihat dalam table sebagai berikut.

Tabel 7 Pengujian Rangkaian Keseluruhan

\begin{tabular}{|c|c|c|c|}
\hline Percobaan & TCS230 & LCD & Loudspeaker \\
\hline Rp. 100.000,- & Ya & $\begin{array}{c}\text { MenampilkanRp, } \\
100.000,-\end{array}$ & Suara 100.000,- \\
\hline Rp. $50.000,-$ & Ya & $\begin{array}{c}\text { MenampilkanRp, } \\
50.000,-\end{array}$ & Suara50.000,- \\
\hline Rp. $20.000,-$ & Ya & $\begin{array}{c}\text { MenampilkanRp, } \\
20.000,-\end{array}$ & Suara20.000,- \\
\hline Rp. 10.000,- & Ya & $\begin{array}{c}\text { MenampilkanRp, } \\
10.000,-\end{array}$ & Suara10.000,- \\
\hline Rp. 5.000,- & Ya & $\begin{array}{c}\text { MenampilkanRp, } \\
5000,-\end{array}$ & Suara5.000,- \\
\hline Rp. 2.000,- & Ya & $\begin{array}{c}\text { MenampilkanRp, } \\
2.000,-\end{array}$ & Suara2.000,- \\
\hline Rp. 1000,- & Ya & $\begin{array}{c}\text { MenampilkanRp, } \\
1.000,-\end{array}$ & Suara1.000,- \\
\hline
\end{tabular}

Dari tabel pengujian rangkaian alat secara keseluruhan, apabila nilai mata uang rupiah terdeteksi maka angka nominal akan di tampilkan di LCD sedangkan loudspeaker akan berbunyi sesuai dengan nominal yang sama di LCD

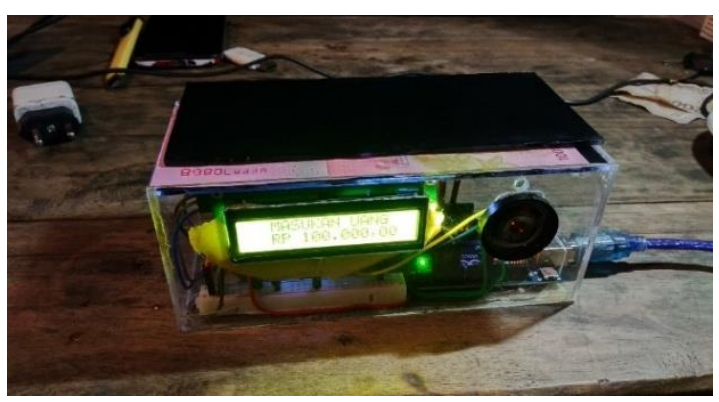

Gambar 9. Pengujian Alat Keseluruhan

\section{PEMBAHASAN}

Dalam hal ini, akan dibahas hasil dari pengujian rangkaian alat yang meliputi pengujian sensor TCS230, pengujian mikrokontroller, pengujian LCD, pengujian DFminiplayer, pengujian loudspeaker, pengujian powersupply dan pengujian rangkaian alat secara keseluruhan yang telah terintegrasi sistemnya secara keseluruhan.

Sensor TCS230 dipasang pada sisi paling atas dari rangkaian alat, untuk mendeteksi nilai nominal uang kertas Rupiah. Dari pengujian yang dilakukan didapatkan besar nilai nominal uang kertas rupiah yang di tampilkan pada LCD didapatkan menunjukkan hasil deteksi sensor TCS230 terhadap mendeteksi setiap mata uang kertas menghasilkan nilai persentase yang berbeda-beda, Melihat hasil yang didapatkan menunjukkan hasil deteksi sensor dalam mendeteksi warna nominal uang kertas rupiah dengan normal dan berfungsi dengan baik.

Mikrokontroller berfungsi sebagai perangkat masukkan suatu program melalui arduino, sehingga alat yang dibuat dapat bekerja dengan baik sesuai dengan sistem kerja.

Kaki - kaki LCD dihubungkan pada pin - pin mikrokontroller dan diberi input tegangan yang berguna untuk mengatur keluaran nilai analog dari masing - masing button yang tersedia pada LCD. Dilakukan upload program sederhana yang tersedia pada program example arduino, seperti helloword untuk menguji rangkaian LCD. Pengujian LCD dilakukan untuk mengetahui besarnilai mata uang kertas rupiah.

Setelah pengujian LCD, dilakukan Pengujian DF miniplayer dilakukan apabila DFminiplayer diberitegangan sebesar 5 volt, maka status $D F$ miniplayer maka(on) /menyala. Sedangkan apabila DF miniplayer tidak diberitegangan, maka status DF miniplayer akan (off) /mati. Dan loudspeaker yang berfungsi untuk mengeluarkan suara sesuai nominal uang yang terdeteksi.

\section{PENUTUP}

\section{Kesimpulan}

Berdasarkan hasil analisis dan pembahasan yang didapat pada penelitian ini dapat disimpulkan :

1. Telah dibuat alat identifikasi nominal uang kertas bagi tuna netra berbasis ATMega328 menggunakan sensor warna TCS230 dan dapat diaplikasikan sebagai pendeteksi nilai uang kertas rupiah dengan cara membaca nilai RGB dari obyek uang kertas rupiah tersebut. Dari hasil uji yg dilakukan di dapat nilai akurasi sensor sebesar 95,7\%, Kondisi fisik uang dan cahaya sekitar sangat berpengaruh dalam pembacaan nilai RGB pada uang kertas rupiah, sedangkan uang yang bentuk fisiknya buruk atau kusut akan mengakibatkan kesamaan nilai RGB, sehingga sensor akan mengalami kesalahan.

2. Aktuator pada penelitian ini terdiri dari, $D F$ miniplayer, dan loudspeaker yang bekerja sesuai dengan output nilai mata uang kertas rupiah yang tertera dalam LCD. Pada saat meletakan uang kertas rupiah diatas sensor TCS230 maka otomatis sensor membaca nilai RGB, apabila sesuai dengan range yang telah di tentukan oleh ATMega328 maka nominal uang kertas rupiah akan ditampilkan di layar LCD dan loudspeaker akan mengeluarkan suara yang 
JEECOM, Vol. 2, No. 2, Oktober 2020

sama berupa nilai mata uang kertas rupiah tersebut.

\section{Saran}

Berdasarkan pengalaman dalam perancangan alat identifikasi nominal uang kertas bagi tuna netra masih jauh dari kata sempurna, untuk mendapatkan hasil yang lebih baiklagi, perlu dilakukan pengembangan pada alat ini;

1. Agar hasil yang di dapat lebih baik lagi dalam pembacaan RGB uang kertas rupiah dapat menggunakan sensor warna TCS yang memiliki tingkat keakuratan yang lebih tinggi sehingga dapat pula mendeteksi uang kertas rupiah yang bentuk fisiknya buruk atau kusut sekalipun.

2. Agar alat ini semakin baik lagi dapat di padukan dengan sensor auto image, sehingga hasil pembacaan tidak hanya nilai RGB melainkan foto asli dari matauang rupiah tersebut.

\section{Daftar Pustaka}

Azhari Hijriyah 2017. Pendeteksi Nominal Uang Kertas Rupiah Berdasarkan Warna Berbasis Mikrokontroler. Palembang : POLITEKIK NEGERI SRIWIJAYA PALEMBANG.

Dian Palupi Restuputri, Ilyas Mas'udin dan kawan - kawan 2018. Membuat Alat Bantu Mengenali Uang Kertas Dengan Kasentra (Kacamata Sensor Tunanetra). Malang : UNIVERSITAS MUHAMMADIYAH MALANG.

Dwi Aryo Porbadi 2014. Deteksi Nominal Uang Kertas Untuk Penyandang Tuna Netra. Malang : UNIVERSITAS BRAWIJAYA.

Widya Hurisantri 2016. Sistem Pendeteksi Warna Dan Nominal Uang Untuk Penyandang Tuna Netra Berbasis Arduino Uno. Palembang : POLITEKNIK NEGERI SRIWIJAYA PALEMBANG.

Widya Mentari 2017. Utami Rancang Bangun Sistem Pendeteksi Keslian Dan Nominal Uang Untuk Tunanetra Berbasis Mikrokontroler. Makassar : UNIVERSITAS ISLAM NEGERI (UIN) ALAUDDIN MAKASSAR.

https://blog.ruangguru.com/pengertian-fungsi-jenisdan-syarat-uang) DIAKSES HARI JUM'AT PUKUL 16:12

http://elektronika-dasar.web.id DIAKSES HARI JUM'AT PUKUL 16:20

(https://www.rs-online.com/designspark/basics-ofatmega328) Diakses hari jum'at pukul 16:23

(http://daytronika.blogspot.comDi

aksesharijum'atpukul 16:26 https://electronicsforu.com/electronicsprojects/two-watt-tba820m-af-amplifier) Diakses hari jum'at pukul 16:30

(https://www.ret.hu/media/product/9384/429100/C D00 000118.pdf) Diakses hari jum'at pukul 16:32

(http://artofcircuits.com/product/microsd-cardreaderwriter-module-level-translator Diakses hari jum'at pukul 16:35

(https://www.jualarduino.com/tcs-3200-sensorwarna) Diakses hari jum'at pukul 16:40 